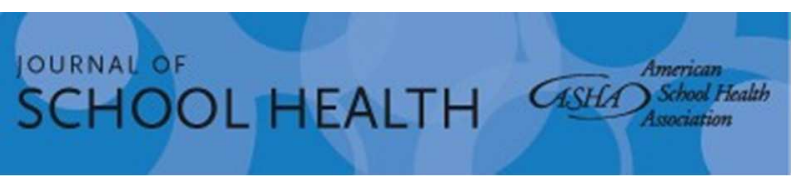

\title{
A PROSPECTIVE COHORT STUDY ON INJURIES AMONG INTENSIVELY PHYSICALLY ACTIVE HIGH SCHOOL STUDENTS
}

\begin{tabular}{|r|l|}
\hline Journal: & Journal of School Health \\
\hline Manuscript ID & JOSH-05-17-RA-161 \\
\hline Manuscript Type: & Research Article \\
\hline Keywords: & $\begin{array}{l}\text { Child \& Adolescent Health, Injury Prevention, Risk Behaviors, Public Health, } \\
\text { Safety Education }\end{array}$ \\
\hline Research Skill Set : & Quantitative Research \\
\hline Settings: & High schools \\
\hline Content: & At risk youth, Child \& Adolescent Health, Injury Prevention \\
\hline Article Type: & Research Article \\
\hline & \\
\hline
\end{tabular}




\title{
A PROSPECTIVE COHORT STUDY ON INJURIES AMONG INTENSIVELY PHYSICALLY ACTIVE HIGH SCHOOL STUDENTS
}

\begin{abstract}
BACKGROUND: The leading cause of non-fatal injuries in age group 14-19 is sports injuries. Purpose of the study was to determine the association between intense physical activity and injury and to identify the circumstances and environment in which injuries are most likely to occur.

METHODS: A prospective cohort study included 698 high school students 15-19 years old, divided into those exposed and those unexposed to intense physical activity. The international standard questionnaire about physical activity (IPAQ) and the metabolic equivalent task score (MET) were used.

RESULTS: The risk of injuries was seven times higher (RR: 7.041; 95\% CI: 6.071, 8.187) and the risk of injuries requiring treatment in health facilities was 15 times higher (RR: 14,717; 95\% CI: 10,$652 ; 20,592)$ in the intensely physically active adolescents. The risk of gaining sports injuries was 11 times higher in the exposed group (RR: 11,212; 95\% CI: 9,013; 14,074), with a significantly higher incidence rate among men (82.9 per 100). Most injuries occurred in football (Inc. 4.4 per $1000 \mathrm{~h}$ ), volleyball (Inc. 3.9 per $1000 \mathrm{~h}$ ) and boxing/kickboxing (Inc. 3.7 per $1000 \mathrm{~h}$ ). CONCLUSIONS: Intensely physically active high school students have a much higher risk of injury, which usually occurs during training or a match.
\end{abstract}

Keywords: adolescents; athletic injuries; physical activity; risk behaviours; youth sport; cohort studies. 
Individuals within the age group 15-19 years are more vulnerable to injury than other young people $^{1-3}$. Although it is unquestionably proven that regular moderate physical activity has a beneficial effect on the health of adolescents, the leading cause of non-fatal injuries in this age group are sports injuries ${ }^{4}$. The intensity of physical activity is particularly relevant for estimation of the optimal dose of physical activity, because the intensity is the major contributor to medical complications caused by exercise ${ }^{5-6}$. Results of several studies suggest that when evaluating the dose-response, potential risks for the target population should also be taken into consideration, not just the dose that induces the greatest health benefits. The more intense the exercises and greater the dose of physical activity, the more frequent are the health risks. In recent years, an increasing number of young people has been involved in intense training, with high levels of competitive activity from an early age, increasing the exposure to injuries ${ }^{7}$. Although most injuries associated with sports and recreational activities are not life-threatening, nonetheless they cause direct pain and suffering, and short-term or long-term incapacity. Also, the consequences, such as abandonment of further sports activity and disability, are more serious with high direct and indirect healthcare and social costs ${ }^{8}$. Withdrawal from further physical activity is a particular public health problem, due to the long-term health consequences of absence of physical activity in adulthood ${ }^{9-11}$.

The purpose of the study was to find the relationship between intense physical activity and injury in a high school cohort and to report how the risk factors for injuries are related to the behaviour and the environment in which the physical activity related injury was most likely to occur. 


\section{METHODS}

A prospective cohort study among the high school students age 15-19 was conducted for 12 months during 2012 and 2013.

\section{Setting}

Five high schools in XXX [Blinded by request from JSH], or $45 \%$ of high school in XXX [Blinded by request from JSH]. A stratified random sample was used, and the strata were determined in the way to provide the territorial representation of the area and type of high schools (professional orientation, age of students). Selection of classes within each school was conducted by the method of random numbers.

\section{Participants}

The sample included 700 respondents from five secondary schools (gymnasium, medical, economic, technical and chemical-technological school). The sample represents $11 \%$ of high school students in XXX [Blinded by request from JSH]. The total sample consisted of $41 \%$ male, $59 \%$ female students.

\section{Instruments}

This preselection process was carried out by the short form of the international standardized questionnaire about physical activity (International Physical Activity Questionnaire - IPAQ Short Form, rev. version 2005) ${ }^{12,13}$. The questionnaire provides separate scores for each type of activity: intense, moderate and easy. The assessment was carried out through engagement in four domains: a) light exercise/walk; b) moderate physical activity; c) intense physical activity, d) the 
time spent at rest (sitting/lying down). The questions were focused on the time a person spent doing physical activity and rest during the previous seven days.

All injuries that happened during the 12 month study period were registered through a structured questionnaire, modified for research purposes (Adolescent Injury Checklist-AIC), completed by students $^{14}$. Injuries that did not require medical aid were also included. The questionnaire on injuries had five domains: Socio-demographic characteristics of the respondents; Habits and behaviour; Physical activity and health; Injuries (type, method and place of origin); Method and the consequences of violence.

Both questionnaires were translated, pilot tested locally and validated.

\section{Procedure}

The students were assigned to the group of those exposed and to the group not exposed to physical activity, based on a preselection process.

Quantifying the level of physical activity was performed by the calculation of metabolic equivalent task (MET). Each type of activity and the required energy was weighted and defined in MET, in order to obtain the result in MET-minutes. Calculation of the total MET score was performed by summing the duration (in minutes) and frequency (in days) of all three types of physical activity during the previous seven days. Respondents were classified into three categories according to the total volume of physical activity, based on the Guidelines for Data Processing and Analysis of the International Physical Activity Questionnaire: a. inactive/sedentary; b. moderately active; c. intensely active.

Adolescents were divided into two groups based on the total MET score in accordance with the prescribed parameters: 
a. The first group consisted of intensively exposed students who met one of two criteria:

- Strong-intensive activity during at least three days a week and with a minimum of 1500 METmin per week accumulated during the week;

- Seven or more days of any combination of medium or strong-intensive activities with a minimum of 3000 MET-min per week accumulated in one week.

b. The second group consisted of students moderately physically active and those physically inactive.

After 12 months, all the students filled out the Adolescent Injury Checklist.

Registration of injuries that required medical intervention was performed by the review of medical documentation in health care institutions (school dispensaries, a sports clinics, general practitioners offices and emergency departments of general hospitals). Data were collected during 12 months. Registration of injuries included data on the first inspection by medical staff, intervention, hospitalization, rehabilitation and exemption from physical activity.

\section{Data Analysis}

The analysis included measurement of the frequency of injuries, their severity, and type of association with a particular type of sport, and the mechanism of their origin, as well as the presence of some forms of risky behaviour in adolescents.

Classification of injuries were carried out according to the International Classification of Diseases $10^{\text {th }}$ revision, group XIX - injuries, poisonings and other consequences of external causes (S00-T98). Analysis of data relating to sport injuries was also performed according to the international classification of external causes of injury (International Classification of External Causes of Injuries (ICEC) version 1.2, 2004). 
During the statistical analysis of the data frequencies, percentages, mean, relative risk (RR), odds ratio chance (OR) and the required number of patients to treat (NNT) were calculated.

Comparisons and determining the existence of statistically significant difference was performed by: Chi2-test (degree of freedom $\mathrm{df}=1$, applied Yates correction); T-test determination of significance of the difference of two independent samples of the $95 \% \mathrm{CI}$; Multivariate analysis of variance (MANOVA): Pillai's Trace, Wilks Lambda; Spearman's correlation connection between variables; Logical regression using standardized $\beta$. 


\section{RESULTS}

Among 698 students enrolled in the study, 345 students were considered to be exposed to intensive physical activity and 353 students were considered as unexposed to intensive physical activity. Two students were excluded as on the repeated screening they didn't meet the inclusion criteria.

In the exposed group males accounted for almost two-thirds (63\%), while in the non-exposed group females made up $80 \%\left(\chi^{2}=128.276, \mathrm{df}=1, \mathrm{p}=0.000\right)$.

Intensively physically active students had significantly better financial status $(\mathrm{t}=3.5700, \mathrm{df}=$ $695, \mathrm{p}=0.0004 ; 95 \% \mathrm{CI}:-0.32557 ;-0.0944)$. They also showed better results in self-evaluation of their health $\left(\chi^{2}=57.888, \mathrm{df}=2, \mathrm{p}=0.000\right)$ and they were more satisfied with their body appearance $(\chi 2=23.080, \mathrm{df}=5, \mathrm{p}=0.000)$. Intensively physically active students were used to make friends more easily $(\chi 2=31.749, \mathrm{df}=3, \mathrm{p}=0.000)$ compared to students who were not intensively physically active.

Risky behaviour is more likely to be frequent in intensively physically active students. A moderate level of correlation between the use of alcohol and participating in a fight was determined in this group $(\mathrm{r}=0.268, \mathrm{p}=0.000)$. Intensively physically active students rarely felt morning fatigue, and they were less frequently on a diet compared to unexposed peers (Table 1). No significant differences were observed between the two groups with respect to smoking, BMI, length of night sleep and time spent watching TV and using a computer.

During 12 months, 289 intensively physically active students were registered with an injury (Inc. 83.8 per 100). In the control group 42 students were registered with an injury (Inc.11.9 per 100). The relative risk of sustaining an injury was seven times higher in intensively physically active 
students $(\mathrm{RR}=7.041 ; 95 \% \mathrm{CI}: 6.071 ; 8.187 ; \mathrm{OR}=38,214 ; \mathrm{NNT}=1.391 ; 95 \% \mathrm{CI}: 1.336$, 1.458), with no significant differences between males and females.

The risk of suffering more than one injury was 1.4 times higher in intensively physically active adolescents, with no significant differences among males and females $(\mathrm{RR}=1.417$; 95\% CI: 1.024, 1.969, OR = 1.906; 95\% CI: 1.044, 3.488; NNT = 6.293), (Figure 1).

The most important social predictor of injuries in the group of physically active adolescents was at least one unemployed parent $(\mathrm{B}=0.139, \beta=0.165, \mathrm{p}=0.018)$ and bullying by peers $(\mathrm{B}=$ $0.219, \beta=0.154, p=0.023)$.

Three-quarters $(76.5 \%)$ of intensively physically active students experienced an injury on a sports field or in a sports hall. Every third student in the control group had an injury at home (35.7\%), (Figure 2). The risk of suffering an injury on the sports field was eight times higher for intensively physically active students $(\mathrm{RR}=8.033 ; 95 \% \mathrm{CI}: 4.517 ; 15,465, \mathrm{OR}=30,888 ; 95 \%$ CI: $12.884 ; 76.210 ; \mathrm{NNT}=1.494 ; 95 \% \mathrm{CI}: 1,324 ; 1,824)$.

Three-quarters (76.5\%) of physically active adolescents suffered an injury on the sports field/hall. A third of the adolescents in the control group suffered an injury at home (35.7\%). The risk of suffering an injury on the sports field was eight times higher in intensely physically active adolescents $(\mathrm{RR}=8.033 ; 95 \% \mathrm{CI}: 4.517 ; 15,465, \mathrm{OR}=30,888 ; 95 \% \mathrm{CI}: 12.884 ; 76.210 ; \mathrm{NNT}=$ $1.494 ; 95 \%$ CI: 1,$324 ; 1,824)$.

The incidence rate of sports injuries for intensively physically active students was 76.2 per 100, and in the control group it was 6.8 per 100 . The relative risk of sustaining a sports injury was eleven times higher in intensely physically active adolescents ( $R R=11,212 ; 95 \% \mathrm{CI}$ : 9,013; 14,074; OR =43,966; 95\% CI: 32,722; 59,166; NNT =1.440). 
A significantly higher incidence rate was registered in males (82.9 per 100) compared to females (65.1 per 100) $\left(\chi^{2}=14.050, \mathrm{df}=1, \mathrm{p}=0.000\right.$, Yates: 13,088$)$

Multivariate analysis showed that the incidence of sports injuries was related to the number of training sessions and the number of hours of exercise in a week (Pillai trace $=0.963 ; \mathrm{F}=$ 3332.73, $\mathrm{df}=(2 / 254) ; \mathrm{p}=0.000)$. Warm-up exercises $(\mathrm{r}=0.481, \mathrm{p}=0.000)$ and BMI $(\mathrm{r}=$ $0.103, \mathrm{p}=0.053)$ did not affect the reduction in the number of sports injuries.

The rate of incidence of sports injuries per 1,000 hours of exposure in the group of intensively physically active students was 2.9 per $1000 \mathrm{~h}$. The highest rate was related to training/a match (4.9 per $1000 \mathrm{~h})$. The incidence rate during leisure activities was 2.5 times lower (1.8 per 1000 h). The lowest rate was related to physical education in schools $(0.4$ per $1000 \mathrm{~h})$.

More than $86 \%$ of all registered sports injuries occurred during organized sports activities, of which two-thirds $(64.7 \%)$ of the injuries were in males $\left(\chi^{2}=33.590\right.$, df $\left.=12, p=0.001\right)$. The incidence rate was the highest for football (4.4 per 1000), volleyball (3.9 per 1000) and boxing/kickboxing (3.7 per 1000), (Table 2).

Almost $90 \%$ of intensively physically active students were not able to be physically active for more than $24 \mathrm{~h}$ after an injury, compared with $65.9 \%$ in the control group $(\chi 2=27.266$, $\mathrm{df}=2$, $\mathrm{p}=0.000$ ). A significantly higher percentage of physically active adolescents required hospital treatment, extended home care and rehabilitation after injury (Table 3).

Temporary disability for a period not longer than six months occurred in $2.8 \%$ of participants in the exposed group while in the control group there was no single case. After sustaining the injury $1.1 \%$ of physically active students had to give up the sport.

The incidence of injuries that required medical treatment was 54.2 per 100 in the group of intensively physically active students and 3.7 per 100 in the control group. The relative risk for 
an injury that requires assistance in a medical institution was almost 15 times higher in the group of intensively physically active students $(\mathrm{RR}=14,717,95 \% \mathrm{CI}: 10,652 ; 20,592 ; \mathrm{OR}=30,952$, 95\% CI: 21,$501 ; 44,738 ; \mathrm{NNT}=1,979)$. Male students suffered from an injury more often $(\chi 2=$ $7.696, \mathrm{df}=1, \mathrm{p}=0.0055)$. 


\section{DISCUSSION}

Intensively physically active students are at significantly higher risk of injury. The relative risk of all self-reported injuries was seven times, and for injuries requiring medical treatment, 15 times higher in this group of students.

Numerous studies have found a significant association between the level of physical activity and injury. Results of the Janssen et al. study ${ }^{15}$ on the population of adolescents in Canada 2001/2002 showed that the probability of severe injury associated with physical activity outside of school grows from moderate to intense physical activity $(\mathrm{OR}=3)$. Regarding physical activity at school, the OR for injuries in the intensively active students was 1.5 . Spinks et al. ${ }^{16}$ found in 2006 the incidence of injury from 67.7 per 100 students in Brisbane, Australia and 78.6\% of injuries were directly related to physical activity.

The most common type of injury found in our study was falls. This is consistent with a number of similar studies and showed that the majority of unintentional injuries among young people occur during organized sports activities, with a significantly higher incidence in males. ${ }^{8,17,18}$

The relative risk of sustaining a sports injury was 11 times higher in the group of intensively physically active adolescents and $85.2 \%$ of those were injured on the sports field, while students from the control group were injured most frequently in the school environment $(37.5 \%)$.

The study by Emery et al. ${ }^{19}$ on a sample of 1466 high school students in Calgary in 2009 showed that the incidence of injury in students who have participated in sports was 60.9 per 100, and more than $40 \%$ of the students suffered more than one injury. 
A study ${ }^{20}$ on 14-19 year old athletes in North Carolina in 2006 showed an incidence of sports injuries of 72.8 per 100 for men and 27.2 per 100 females. The incidence rates per 1,000 hours of exposure in intensely physically active respondents are approximately near the values in our study, for 12 tested sports they were 2.1 per $1000 \mathrm{~h}$, and at matches 5.0 per $1000 \mathrm{~h}$.

Our study showed that injuries occur almost six times more often in organized sports. The highest incidence rate of injuries was recorded during training or a match (4.9 per $1000 \mathrm{~h}$ ). According to data from Youth sports safety, $62 \%$ of injuries in organized sport occurred during training ${ }^{21}$. Janssen et al. ${ }^{15}$ showed that the most common injuries occurred in physically active students in organized sports activities outside school $(\mathrm{OR}=2.98)$. A study by Verhaegen et al. ${ }^{22}$ in 2009 showed that the injuries occurred mostly among students in organized sport.

A quarter of all injuries of physically active students in our study which happened in organized sports was related to football (4.4 per 1000). According to the results of various studies, the incidence rate of injuries related to football was in the range of 4.6 to 7.9 per $1000 .^{23}$ Multivariate analysis showed that a large number of training sessions and number of hours of exercise increases the risk of injury. The use of protective sports equipment and warm-up exercises did not affect the reduction in the number of injuries in our patients.

Although numerous studies have shown that warming up and stretching leads to better flexibility of ligaments, there is not enough firm evidence about reducing the risk of injury. ${ }^{24}$ Similarly, Thacker et al. ${ }^{25}$ found that there was insufficient evidence that warming up and stretching before training have an impact on reducing the risk of injury.

The intensity of physical activity had no influence on reducing risky behaviour in adolescents, such as the use of alcohol and violent behaviour. Results of the study confirm the empirical 
findings of other studies, which support the claim that physical activity does not reduce the level of violence among young people. ${ }^{26-28}$

\title{
Limitations
}

Limitations of use of self-reporting techniques are now well documented. The most common problems in the precision and accuracy of reporting on the level of physical activity are: misinterpretation of questions by respondents, the difficulty in accurately defining the duration and intensity of physical activity on the basis of memory and / or misinterpretation of the results obtained by the researchers. It was found that the questionnaires completed by respondents themselves less accurate than those completed by the interviewer. ${ }^{29}$ Also, this method includes some other limitations: the difficulty in estimating the frequency, duration and intensity of physical activity, capturing the different domains of physical activity, the provision of socially desirable response, and cognitive limitations provided data on the basis of memory. ${ }^{30,31}$

\author{
Conclusions \\ Intensively physically active high school students have a much higher risk of injury, which \\ usually occurs during training or a match. There is no difference in overall injury incidence \\ among boys and girls, but the incidence of sports injuries is significantly higher among boys. \\ Inactive or moderate physically active high school students more often have at least one parent \\ unemployed and they are more unsatisfied with their parents' earnings. In contrary, intensively \\ physically active students are more likely to exhibit risk behaviours (to be involved in fights, to \\ get drunk or to carry weapons).
}


The risk of injuries among intensively physically active high school students emphasises the need for the appropriate policies and prevention programmes, which would include better education of coaches, organisers or sports events, referees, parents and students themselves.

\section{IMPLICATIONS FOR SCHOOL HEALTH}

The role of schools in promoting physical activity is essential and benefits of physical activity to students are well known. However, schools need to provide safe environment for physically active students and to prevent sport-related injuries.

It is necessary to establish a system to monitor injuries in school and to record and evaluate all injuries. Periodical evaluations will reveal injury prevention gaps and should lead to injury prevention improvement activities in schools.

Special attention should be paid to improving the quality of sports and recreation in schools through:

- education and preparation of children and adolescents to participate in sports activities,

- impact on the behaviour of young people in sport and recreation,

- adequate supervision of training and exercises by trained licensed trainers, including specific training in injury prevention,

- adequate quality and suitability for a specific purpose sports fields (accessibility, security),

- provision of adequate sports and protective equipment.

\section{Human Subject Approval Statement}


The research was approved by the Board of Ethics of the University of XXX [Blinded by request from JSH] and the Board of Ethics of the XXX [Blinded by request from JSH].

\section{REFERENCES}

1. Sleet D, Ballesteros M, Borse N. A Review of unintentional injuries in adolescent. Annu Rev Public Health. 2010;31:195-212.

2. Mujkic A, Duric P, Milosevic M, Geres N.. Comparison between traffic injuries related deaths among children in Croatia and Serbia. Paediatrics Today. 2015;11(2).

3. Duric P. Child mortality in Serbia due to accidents. Paediatria Croatica. 2015(Supl 1):161-6.

4. Hallal PC, Victoria CG, Azevedo MR, Wels JCK. Adolescent physical activity and health: a systematic review. Sports Med .2006;36(12):1019-30.

5. Kolarov N. Child and sport: physical activity burden in children and youth [in Serbian]. Sportska medicina. 2005;5(1):22-26.

6. Frisch A, Croisier JL, Urhausen A, Seil, R, Theisen, D.. Injuries, risk factors and prevention initiatives in youth sport. Br Med Bull. 2009;92(1):95-121.

7. Akseki D, Erduran M, Kaya D. Sports injuries and proprioception: current trends and new horizons, in Sports injuries prevention, diagnosis, treatment and rehabilitation. Berlin: Berlin Heidelberg Springer; 2012. 
8. Kumpula H, Paavola M. Injuries and risk taking among young people in Europe - the European situation analysis. EU-Project Adrisk. Helsinki: National Public Health Institute; 2008.

9. Trudeau F, Laurencelle L, Shephard RJ. Tracking of physical activity from childhood to adulthood. Med Sci Sports Exerc. 2004;36(11):1937-43.

10. Taylor WC, Blair SN, Cummings SS. Wun CC, Malina RM. Childhood and adolescent physical activity patterns and adult physical activity. Med Sci Sports Exerc. 1999;31(1):118-23.

11. Craggs C, Corder K, van Sluijs EM, Griffin, SJ. Determinants of change in physical activity in children and adolescents: a systematic review. Am J Prev Med. 2011;40(6):645-58.

12. International Physical Activity Questionnaire. Guidelines for data processing and analysis of the international physical activity questionnaire. Available at: https://docs.google.com/viewer?a=v\&pid=sites\&srcid=ZGVmYXVsdGRvbWFpbnx0aG VpcGFxfGd4OjE0NDgxMDk3NDU1YWRIZTM Accessed 3 May 2017.

13. Ridley K, Ainsworth BE, Olds TS. Development of a compendium of energy expenditures for youth. Int J Behav Nutr Phys Act. 2008;5:45-53.

14. Chapman RL, Buckley LD, Sheehan MC. The Development of the extended adolescent injury checklist (E-AIC): A measure for injury prevention program evaluation. Youth Stud Austral.2011;30(1):49-58.

15. Janssen I, Dostaler S, Boyce WF, Pickett W. Influence of multiple risk behaviours on physical activity-related injuries in adolescents. Pediatrics. 2007;119(3): 672-80. 
16. Spinks AB, McClure RJ, Bain C, Macpherson A. Quantifying the association between physical activity and injury in primary school-aged children. Pediatrics. 2006;118(1):e4350.

17. Mattila V. Injuries and their risk factors in Finnish adolescents. [Dissertation]. Tampere: University of Tampere, School of Public Health; 2005.

18. Gianoudis J, Webster KE, Cook J. Volume of physical activity and injury occurrence in young basketball players. $J$ Sports Sci Med. 2008;7(1):139-43.

19. Emery CA, Meeuwisse WH, McAllister JR. Survey of sport participation and sport injury in Calgary and area high schools. Clin J Sport Med; 2006;16(1):20-6.

20. Knowles SB, Marshall SW, Bowling JM. A Prospective study of injury incidence among North Carolina high school athletes. Am J Epidemiol; 2006;164(12):1209-21.

21. National Athletic Trainers' Association. Youth sports safety statistics, 4th annual youth sports safety summit-national action plan for sports safety; 2013 Feb 5-6, Washington: Youth Sports Safety Alliance; 2013.

22. Verhagen EALM, Collard DCM, Chin A, Paw MJM, van Mechelen WAA. Prospective cohort study on physical activity-related injuries in 10-12 year old children. $B r J$ Sports Med. 2009;43(13):1031-5.

23. Caine D, Maffulli N, Caine C. Epidemiology of injury in child and adolescent sports: injury rates, risk factors, and prevention. Clin Sports Med. 2008;27(1):19-50.

24. O'Sullivan K, Murray E, Sainsbury D. The effect of warm-up, static stretching and dynamic stretching on hamstring flexibility in previously injured subjects. $B M C$ Musculoscelet Disord. 2009;10:37. 
25. Thacker SB, Gilchrist J, Stroup DF, Kimsey CD. The impact of stretching on sports injury risk: a systematic review of the literature. Med Sci Sports Exerc. 2004;36(3):371-8.

26. Endersen IM, Olweus D. Participation in power sports and antisocial involvement in preadolescent and adolescent boys. $J$ Child Psychol Psychiatry. 2005;46(5):468-78.

27. Rutten E, Stams GJ, Biesta GJ, Schuengel C, Dirks E, Hoeksma JB. The contribution of organized youth sport to antisocial and prosocial behaviour in adolescent athletes. $J$ Youth Adolescence. 2007;36:255-64.

28. Popadic D, Bacanac LJ, Golic, Petrovic M, Vidovic M.. Violent behaviour among children and youth in sport: research results and recommendations. Prevention of conflicts and violent behaviour among children and youth in sport as part of the local community [in Serbian]. Belgrade: Ministry of Youth and Sport; 2011.

29. Montoye HJ, Taylor HL. Measurement of Physical Activity in Population Studies: a Review. Hum Biol 1984; 56:195-216.

30. Sallis JF, Saelens BE. Assessment of Physical Activity by Self-report: Status, Limitations, and Future Diractions. Res Q Exerc Sport 2000; 71(2):S1-S14.

31. Rangul V, Holmen TL, Kurtze N, Cuypers K, Midthjell K. Reliability and Validity of two Frequently Used Self-administered Physical Activity Questionnaires in Adolescents. BMC Med Res Methodol 2008; 8:47-57. 


\section{Figure 1. Frequency of Injuries during 12 Months}

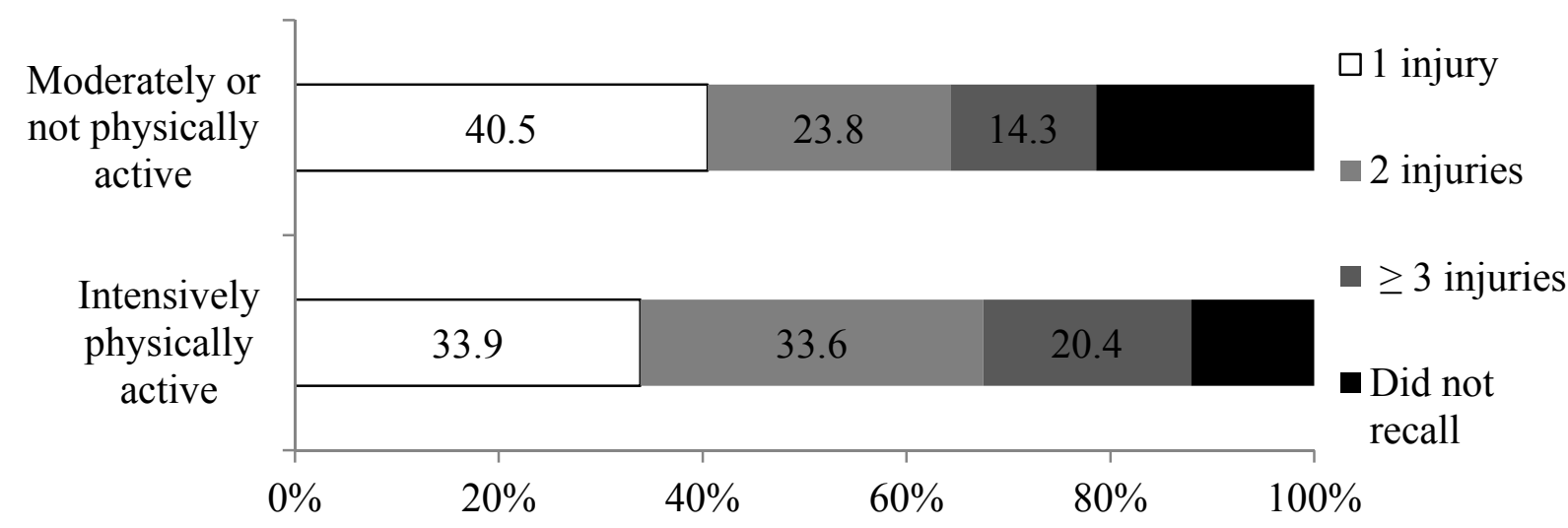


Figure 2. Location/Terrain Where the Injury Occurred

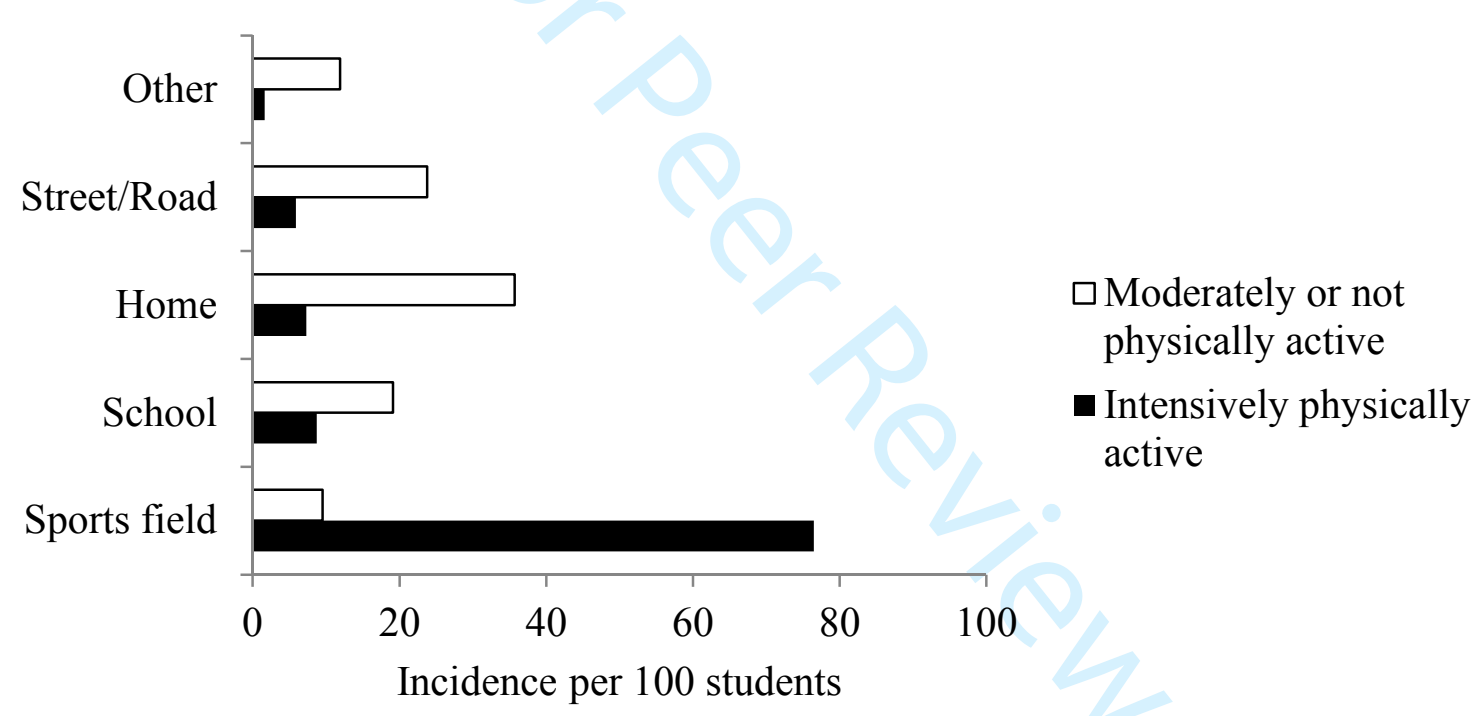




\section{Table 1. Sociodemographic differences and differences in group behaviour}

\begin{tabular}{|c|c|c|c|}
\hline & $\begin{array}{c}\text { Intensely } \\
\text { physically active } \\
\%\end{array}$ & $\begin{array}{c}\text { Physically inactive } \\
\text { or moderately } \\
\text { active \% }\end{array}$ & Significance \\
\hline \multicolumn{4}{|c|}{ Sociodemographic characteristics } \\
\hline Great success in school & 28.1 & 39.1 & $\begin{array}{l}\mathrm{t}=3.3933, \mathrm{df}=696, p=0.0007 \\
95 \% \text { CI: } 0.09683 ; 0.36317\end{array}$ \\
\hline $\begin{array}{l}\text { At least one parent } \\
\text { unemployed }\end{array}$ & 21.6 & 41.2 & $\begin{array}{c}t=3.9677, d f=685, p=0.0001 \\
95 \% C I:-0.56817 ;-0.19183\end{array}$ \\
\hline $\begin{array}{l}\text { Satisfactory financial } \\
\text { status of parents }\end{array}$ & 44.1 & 33.2 & $\begin{array}{l}\mathrm{t}=3.5700, \mathrm{df}=695, \mathrm{p}=0.0004 \\
95 \% \text { CI: }-0.32557 ;-0.09443\end{array}$ \\
\hline \multicolumn{4}{|l|}{ Habits and behaviour } \\
\hline Easily make friends & 95.6 & 84.7 & $\chi^{2}=31.749, \mathrm{df}=3, \mathrm{p}=0.0001$ \\
\hline
\end{tabular}


Drunkenness $\geq 10$ times

11.7

6.2

$\chi^{2}=13.382, \mathrm{df}=4, \mathrm{p}=0.010$

in last 12 months

Participation in a fight

3.8

0.9

$\chi^{2}=3 ., 868, \quad \mathrm{df}=3, \quad \mathrm{p}=0.0001 ;$

$\geq 2$ in last 12 months

$\mathrm{r}=0.268, \mathrm{p}=0.0001$

Carry weapons/often or

5.2

1.2

$\chi^{2}=11.188, \quad \mathrm{df}=4, \quad \mathrm{p}=0.025$

always

$\mathrm{r}=0.297, \mathrm{p}=0.0001$

\section{Self-assessment of health}

Feels very healthy

67.3

38.5

$\chi^{2}=57.888, \mathrm{df}=2, \mathrm{p}=0.0001$

Satisfied with body $\quad 57.4$

48.2

$\chi^{2}=23.080, \mathrm{df}=5, \mathrm{p}=0.0001$

appearance

Morning fatigue $\geq 4$

13.9

18.4

$\chi^{2}=13.598, \mathrm{df}=3, \mathrm{p}=0.004$

times a week

On a diet

22.0

38.2

$\chi^{2}=21.750, \mathrm{df}=1, \mathrm{p}=0.0001$ 


\section{Table 2. Injuries in organized sports among exposed adolescents}

\begin{tabular}{ccc}
\hline Sport & \% injured & Inc. per $1000 \mathrm{~h}$ \\
\hline Football & 24.9 & 4.4 \\
Volleyball & 10.8 & 3.9 \\
Boxing/kickboxing & 9.8 & 3.7 \\
Basketball & 8.7 & 3.4 \\
Dance/folklore & 7.6 & 3.4 \\
Tennis & 6.9 & 3.5 \\
Body building/gym & 6.9 & 2.0 \\
Water polo & 3.6 & 2.2 \\
Handball & 3.2 & 3.0 \\
Martial arts & 2.8 & 0.8 \\
Athletics & 2.5 & 3.0 \\
Swimming & 1.8 & 1.8 \\
Gymnastics & 0.7 & 2.6 \\
Other & 9.8 & 2.0 \\
\hline
\end{tabular}


Table 3. Consequences and Treatment of Injuries

\begin{tabular}{lccc}
\hline \multicolumn{1}{c}{$\begin{array}{c}\text { Consequences and } \\
\text { treatment }\end{array}$} & $\begin{array}{c}\text { Intensely } \\
\text { physically } \\
\text { active } \%\end{array}$ & $\begin{array}{c}\text { Physically } \\
\text { inactive or } \\
\text { moderately } \\
\text { active } \%\end{array}$ & Significance \\
\hline $\begin{array}{l}\text { No physical activity for } \\
\geq 24 \text { h }\end{array}$ & 89.9 & 65.9 & $\chi^{2}=27.266, \mathrm{df}=2, \mathrm{p}=0.001$ \\
$\begin{array}{l}\text { No physical activity for } \\
\geq 1 \text { month }\end{array}$ & 6.2 & 9.4 & $\chi^{2}=9.815, \mathrm{df}=6, \mathrm{p}=0.133$ \\
$\begin{array}{l}\text { Extended home care } \\
\text { Nospital treatment }\end{array}$ & 42.6 & 21.4 & $\mathrm{RR}=1.986,95 \% \mathrm{CI}:$ \\
Rehabilitation & 8.7 & 4.8 & $\chi^{2}=0.312, \mathrm{df}=1, \mathrm{p}=0.5764$ \\
& 12.5 & 4.8 & $\mathrm{RR}=2.618,95 \% \mathrm{CI}:$ \\
& & & $0.884 ; 8.518 ; \mathrm{OR}=2.848$
\end{tabular}

